\title{
Application of Intracellular Alkaline Phosphatase Activity Measurement in Detection of Neutrophil Adherence In Vitro
}

\author{
Katarzyna Bednarska, Magdalena Klink, and Zofia Sulowska \\ Department of Experimental Immunology, Centre for Medical Biology, Polish Academy of Sciences, Lodowa 106, Lodz 93-232, Poland
}

Received 28 April 2006; Accepted 13 July 2006

\begin{abstract}
We have proposed the use of the fluorimetric method with 4-methylumbelliferyl phosphate (4-MUP) specific substrate for the alkaline phosphatase determination in the neutrophil adhesion assay. We provide evidence that the endogenous neutrophil alkaline phosphatase (NAP) activity evaluation is reliable to quantify neutrophil adhesion at a wide range of cell numbers $\left(10^{4}-10^{6}\right)$. The results obtained by fluorimetric NAP activity test correlate to the results of adherence evaluated using the MTT reduction assay. The fluorimetric NAP activity test may be applied for resting as well as activated neutrophils without the risk of the activators interferences into the test. The alkaline phosphatase survey with the use of 4-MUP substrate is recommended herein as a sensitive, repeatable, simple, and reliable method of the neutrophil adherence determination in vitro.
\end{abstract}

Copyright (C) 2006 Katarzyna Bednarska et al. This is an open access article distributed under the Creative Commons Attribution License, which permits unrestricted use, distribution, and reproduction in any medium, provided the original work is properly cited.

\section{INTRODUCTION}

Polymorphonuclear neutrophils (PMNs) are implicated in an inflammatory response of the host. The adhesion of neutrophils to the vessel wall and extracellular matrix proteins is required for neutrophil transendothelial migration to the sites of inflammation [1].

Numerous methods have been proposed for a study of neutrophil adhesion in vitro. Most of them are based on an estimation of the cell adhesion using colorimetric or fluorimetric tests. However, colorimetric methods require relatively high number of cells that may result in the aggregate formation interfering with the adhesion assay [2]. Among colorimetric methods, the MTT (3-(4,5-dimethylthiazol-2-yl)-2,5-diphenyltetrazolium bromide) reduction assay is routinely employed to quantify the neutrophils adherence in vitro $[3,4]$. This assay is based on the reduction of tetrazolium salt to formazan induced by live and metabolically active cells [5]. However, there is evidence that the MTT reduction test may give false positive results for macrophage cell lines expressing nitric oxide synthase (iNOS) [6], or when substances interfering with the color are applied [7].

Fluorimetric methods with the use of fluorescent reagents are free from these disadvantages, they are much more sensitive, require a smaller cell number and the reagents relatively rarely interfere with other chemicals [8-10]. However, some fluorescent dyes like fluorescein or calcein derivatives require prelabeling of the cells which may result in cytotoxic effects [11].

The application of fluorogenic substrates for detection of intracellular phosphatases activity has been proposed as the method that helps to overcome the above mentioned limitations [12]. Phosphatases are widely distributed enzymes in many types of cells and are used as cellular markers for an assessment of cell quantity [13]. The neutrophil alkaline phosphatase (NAP) is localized in secretory vesicles and it is relocalized to the cellular membrane following the cell stimulation [14-16]. The colorimetric measurement of the total cellular alkaline phosphatase activity, that is, stored in vesicles and expressed in the membrane, has been recommended by Santini et al [17] for determination of the neutrophils adherence to microtitre plates.

The alkaline phosphatase fluorogenic substrate 4-methylumbelliferyl phosphate (4-MUP) has been extensively used in enzymatic studies, immunofluorescence procedures $[18,19]$, and for the enzyme subcellular localization [20]. Non-fluorescent 4-MUP substrate is hydrolysed by the enzyme into stable fluorescent product, 7-hydroxy-4-methylcoumarin that can be measured spectrofluorimetrically. So far the 4-MUP substrate has not been applied for NAP activity measurements.

The aim of this study was to use the 4-MUP substrate for measurements of neutrophil alkaline phosphatase activity 
and apply whole-cell NAP fluorimetric survey as the competitive method to quantify the neutrophil adhesion in vitro.

Neutrophil adherence measured by the fluorimetric assay of NAP activity was compared with its adherence evaluated using the MTT reduction assay as the reference test.

\section{MATERIALS AND METHODS}

\section{Chemical reagents}

Polymorphprep was obtained from Axis Shield (Norway). RPMI-1640 medium, Hanks' balanced salt solution (HBSS), 3-[4,5-dimethylthiazol-2-yl]-2,3-diphenyltetrazolium bromide (MTT), 2-propanol, phorbol 12-myristate 13-acetate (PMA), tumor necrosis factor $\alpha$ (TNF- $\alpha$ ) human recombinant, genistein, 4-methylumbelliferyl phosphate (4-MUP), Tris, $\mathrm{NaCl}, \mathrm{MgCl}_{2}$, Triton $\mathrm{X}-100$ were purchased from Sigma-Aldrich (USA). Fetal Bovine Serum (FBS) was obtained from GIBCO BRL (UK).

\section{Neutrophil isolation}

Heparinized blood was collected from healthy donors. Neutrophils were isolated as described previously [4]. Briefly, the $5 \mathrm{~mL}$ blood samples were layered onto the $5 \mathrm{~mL}$ of Polymorphprep and centrifuged at $500 \mathrm{xg}$ for 30 minutes. The top band containing mononuclear cells was removed while the lower one containing neutrophils was collected. The neutrophils were washed twice with PBS. The neutrophils viability (> 95\%) and cell purity (> 95\%) were assessed by trypan blue exclusion and May-Grünwald-Giemsa staining, respectively. Different numbers of cells ranging from $1 \times 10^{3}$ cells $/ \mathrm{mL}$ to $2 \times 10^{6}$ cells $/ \mathrm{mL}$ were prepared by serial dilutions of cell suspension in RPMI-1640 medium supplemented with $10 \%$ heat-inactivated FBS. The protocol of these studies was approved by The Regional Commission for Ethics in Research and it was conformed to the provisions of the Declaration of Helsinki.

\section{Fluorimetric measurements of the endogenous NAP activity}

The endogenous phosphatase activity was measured in neutrophils with the use of the fluorogenic substrate 4methylumbelliferyl phosphate (4-MUP). The following parameters were optimized: the substrate concentration, the cell lysis time, and the cell lysis temperature.

The stock solution of substrate 4-MUP was prepared in Tris-NaCl buffer (Tris $50 \mathrm{mM}, \mathrm{NaCl} 150 \mathrm{mM}, \mathrm{pH} 10$ ) at the concentration of $1 \mathrm{mg} / \mathrm{mL}$ and stored frozen at $-20^{\circ} \mathrm{C}$. Cells were lysed with Triton X-100 lysis buffer (Tris $50 \mathrm{mM}, \mathrm{NaCl}$ $150 \mathrm{mM}, 1 \%$ Triton X-100, pH 10) containing 4-MUP substrate at $4^{\circ} \mathrm{C}, 37^{\circ} \mathrm{C}$ and room temperature.

The optimum of substrate concentration was determined as follows. An aliquot of $1 \mathrm{~mL}$ of neutrophil suspension $\left(10^{5}\right)$ in U-bottom polystyrene tubes (Nunc) was centrifuged at $500 \mathrm{xg}$ for 10 minutes at room temperature. The cells in the pellet were lysed in $150 \mu \mathrm{L}$ of the Triton X-100 buffer containing the 4-MUP substrate at the range of concentrations $10-100 \mu \mathrm{g} / \mathrm{mL}$ (30 or 60 minutes, room temperature). The samples were gently shaken over the incubation time. Finally, aliquots of $120 \mu \mathrm{L}$ of lysates were transferred to the 96-well black plates (Labsystem, Finland). The fluorescence intensity (RFU, relative fluorescence units) was measured in Fluoroscan Ascent FL fluorometer (Labsystem, Finland; excitation at $360 \mathrm{~nm}$ and detection at $450 \mathrm{~nm}$ wavelengths). The average fluorescence, based on the data from four repeats, was calculated for each sample. The background fluorescence intensity of the substrate alone without cells was also measured and subtracted from the fluorescence intensity of the samples. The range of linear dependence between the substrate concentration and the fluorescence intensity was estimated. An optimum substrate concentration was applied for further experiments.

For the determination of time lysis the cells $\left(10^{3}-5 \times 10^{5}\right)$ were centrifuged ( $500 \mathrm{xg}, 10$ minutes); the pellet was resuspended in $500 \mu \mathrm{L}$ of the lysis Triton X-100 buffer containing 4-MUP substrate $(25 \mu \mathrm{g} / \mathrm{mL})$ and incubated for $30,40,60$, and 120 minutes at room temperature with shaking. Finally, $120 \mu \mathrm{L}$ aliquots of the lysates were transferred to the 96-well black plates in four repeats (four wells) and the fluorescence intensity (RFU) was measured. The effect of incubation time on the relationship between fluorescence intensity and quantity of neutrophils was determined. The linear regression was calculated.

\section{Neutrophil quantity determination by endogenous NAP activity}

Neutrophils at the range of cell numbers $\left(10^{3}-2 \times 10^{6}\right)$ were centrifuged and lysed with $500 \mu \mathrm{L}$ lysis Triton X-100 buffer containing 4-MUP substrate $(25 \mu \mathrm{g} / \mathrm{mL})$, for 1 hour at room temperature with gentle shaking $(200 \mathrm{rpm}$; Wellmix, Labsystem, Finland). Finally, $120 \mu \mathrm{L}$ aliquots of the lysates were taken for fluorescence measurements in triplicate. The experiment was repeated for at least 6 donors. The linear relationship between alkaline phosphatase activity and the cell number was compared to the results obtained for the reference MTT reduction test (described below).

\section{Adhesion assay}

Aliquots of $0.5 \mathrm{~mL}$ of neutrophil suspensions $\left(10^{3}-2 \times 10^{6}\right.$ cells) were distributed into 24-well polystyrene Nunclon plates (Nunc, Denmark). TNF- $\alpha$ (at the concentration range $1-100 \mathrm{ng} / \mathrm{mL}$ ) was added to the cells, as the activator of cell adhesion. The volume of cell suspensions was filled up to $1 \mathrm{~mL}$ with RPMI-1640 medium supplemented or not with $10 \%$ of FBS (as indicated). In some experiments the neutrophils were pretreated with genistein at the concentrations of $1 \mu \mathrm{M}, 10 \mu \mathrm{M}$, and $50 \mu \mathrm{M}$ for 15 minutes $\left(37^{\circ} \mathrm{C}\right.$, $\left.5 \% \mathrm{CO}_{2}\right)$. Genistein is an inhibitor of protein tyrosine kinases that are involved in the process of neutrophil adhesion (Kelly et al [21]). In all experiments, the neutrophils were subsequently incubated for 45 minutes at $37^{\circ} \mathrm{C}$, with $5 \% \mathrm{CO}_{2}$. After the incubation, non-adhered cells were gently 
removed by pipette and the layer of adhered cells was gently washed with $\mathrm{HBSS}$ prewarmed to $37^{\circ} \mathrm{C}$. Adherent cells were then subjected to the NAP activity and the MTT reduction tests directly in plates to avoid additional manipulations.

\section{The determination of neutrophil adherence by endogenous NAP activity assay}

Aliquots of $500 \mu \mathrm{L}$ of Triton X-100 lysis buffer with 4-MUP substrate $(25 \mu \mathrm{g} / \mathrm{mL})$ were added to the wells with adherent cells in the 24-well plate. Samples were incubated at room temperature with gentle shaking. Aliquots of $120 \mu \mathrm{L}$ of the cell lysates were transferred to the 96-well black plates in 3-4 repeats and the intensity of fluorescence was measured as described above. To measure the endogenous NAP activity in the total cell number taken for the adhesion assay, the cells distributed into 24-well polystyrene Nunclon plates were centrifuged ( $550 \mathrm{xg}, 5$ minutes) and the pellet was subjected to the NAP activity test.

\section{The MTT reduction assay}

The neutrophil adherence assay was based on the method described previously by Oez et al [3]. Aliquots of $250 \mu \mathrm{L}$ of MTT solution ( $2 \mathrm{mg} / \mathrm{mL}$ in PBS) containing $10 \mathrm{ng} / \mathrm{mL}$ of PMA were added to the wells with adhered cells in the 24-well plate. (Live cells convert the yellow tetrazolium salt, MTT to the blue formazan product.) After an incubation of cells with MTT solution (60 minutes), 2-propanol was added (500 $\mu \mathrm{L})$ to dissolve the formazan produced in neutrophils. Aliquots of $100 \mu \mathrm{L}$ of dissolved formazan were transferred into the 96-well plate in 3 repeats. The absorbance was measured at $560 \mathrm{~nm}$ and at $630 \mathrm{~nm}$ (reference) wavelengths (ELISA reader Multiscan RC; Labsystem, Finland). The absorption of formazan is directly related to the number of metabolically active (living) neutrophils.

To measure the total MTT reduction in the total cell number, the cells distributed into 24 -well polystyrene Nunclon plates were centrifuged (550 xg, 10 minutes) and the pellet was subjected to the MTT reduction test.

\section{Interferences of TNF- $\alpha$ in NAP activity and MTT reduction tests}

For the study of a possible interferences of TNF- $\alpha$-stimulation in the NAP activity and MTT reduction tests, the effects of TNF- $\alpha$ on the 4-MUP substrate hydrolysis and the formazan production were determined, respectively. Neutrophils were incubated with TNF- $\alpha$ or without TNF- $\alpha$ (control) (45 minutes at $37^{\circ} \mathrm{C}$ with $5 \% \mathrm{CO}_{2}, 10^{6}$ cells/well in 24well plate), then centrifuged (500 xg, 10 minutes) and subjected to the NAP activity and MTT reduction tests. The values obtained for TNF- $\alpha$-stimulated cells were compared to the control values by pair-wised Student $t$ test calculated for at least 8 donors. The influence of TNF- $\alpha$-stimulation on 4-MUP substrate hydrolysis (RFU values) as well as formazan production (OD values) was calculated according to the formula

$$
\begin{aligned}
& \text { Interference } \\
& \qquad=100 \% \times\left(\frac{\mathrm{TNF} \alpha \text { stimulated cells }- \text { control cells }}{\text { control cells }}\right) .
\end{aligned}
$$

To exclude the possibility of neutrophil alkaline phosphatase release from TNF- $\alpha$-stimulated neutrophils, the enzyme activity was measured also in the supernatants collected from the centrifuged suspensions of neutrophils after activation with different doses of TNF- $\alpha(10-100 \mathrm{ng} / \mathrm{mL})$.

\section{Statistical data analysis}

The normality of data distribution was examined by ShapiroWilk W test. The correlation between NAP activity and the MTT reduction assays was tested by Pearson correlation coefficient $(r)$. The linear relationship of fluorescence intensity to cell number was verified by linear regression. The effects of different doses of TNF- $\alpha$ and of genistein on neutrophil adhesion were tested by ANOVA/Dunnett's test. The interference effects of TNF- $\alpha$ possible in NAP activity and MTT reduction measurements were verified by paired-wised Student $t$ test. The value $P \leq .05$ was considered significant. Detection limits of both methods were estimated for means of the blank sample plus 2 times the standard deviation (10 replicates) and calculated from linear regression equations.

\section{RESULTS}

\section{Application of 4-MUP substrate for endogenous neutrophil alkaline phosphatase activity determination}

The fluorogenic substrate 4-methylumbelliferyl phosphate (4-MUP) was introduced to determine endogenous neutrophil phosphatase activity. The cells were incubated with the 4-MUP substrate in lysis Triton X-100 buffer at pH 10an optimum conditions for determination of alkaline phosphatase located in cell membrane as well as stored in neutrophil granules. The appropriate substrate concentration, lysis temperature, and lysis time were determined.

The linearity of the relationship between fluorescence intensity and 4-MUP concentration was approximated by tangent line calculation (Figure 1). As it is shown, the relationship is linear at the substrate concentrations range 15$35 \mu \mathrm{g} / \mathrm{mL}$. The 4 -MUP concentration of $25 \mu \mathrm{g} / \mathrm{mL}$ was applied for further experiments.

The relationship between fluorescence intensity and the time of cells incubation with the substrate was determined at a cell number ranging $10^{3}-5 \times 10^{5}$ (Figure 2). It is shown that the fluorescence intensity measured after 30, 40, and $60 \mathrm{~min}-$ utes of incubation is linear over the range of the cell number used. Incubation time of 60 minutes was applied for our experiments.

The cells incubation in the lysis buffer plus the substrate was proceeded at $4^{\circ} \mathrm{C}, 37^{\circ} \mathrm{C}$, and room temperature. The room temperature was determined as optimum. 


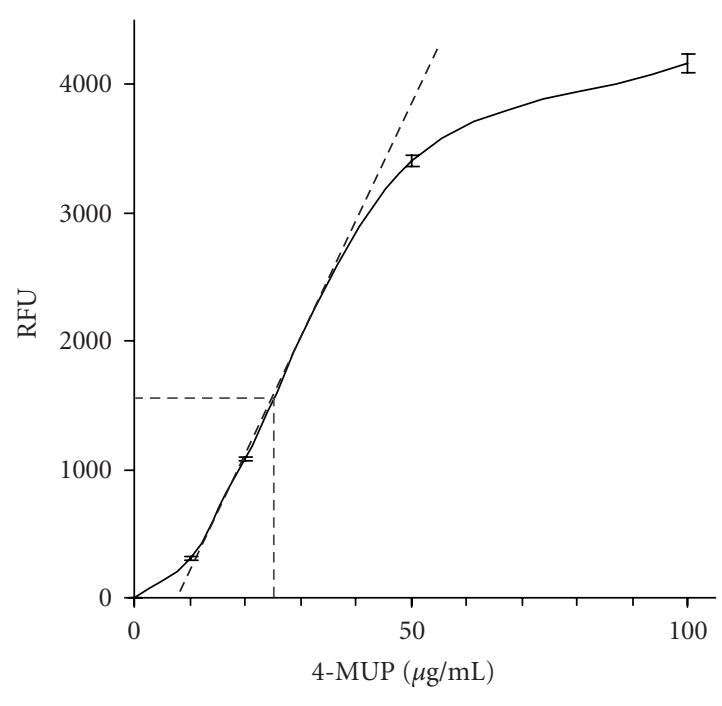

FIGURE 1: The fluorescence intensity in relation to 4-MUP substrate concentration. Neutrophils $\left(10^{5}\right.$ cells) were incubated in Triton X100 lysis buffer containing the 4-MUP substrate at the range of concentrations $10-100 \mu \mathrm{g} / \mathrm{mL}$; the fluorescence intensity (RFUrelative fluorescence units) of cell lysates was measured over substrate concentration range. Each point represents the average fluorescence intensity \pm SEM calculated from four wells. The linearity of the relationship of fluorescence intensity and substrate concentration was approximated on the basis of the tangent line (dashed). A substrate concentration $25 \mu \mathrm{g} / \mathrm{mL}$ was applied for further experiments.

The NAP activity measured in the lysates of freshly prepared cells as well as in those of frozen cells $\left(-20^{\circ} \mathrm{C}\right)$ remained unchanged, what allowed to collect and store the material from different donors.

\section{The endogenous NAP activity assay for the cell number determination}

Figure 3 shows that the linearity of the fluorescence intensity in relationship to the number of neutrophils was between $10^{3}$ cells and $10^{6}$ cells $(r=0.998)$. The detection limit of the method is $2.4 \times 10^{3}$ cells. The reference MTT reduction assay is linear at a narrow range of cell number $10^{5}-10^{6}$ $(r=0.955)$ and the detection limit of this method is $3 \times 10^{4}$ cells (Figure 3, dotted line). The intertest variability was less than $5 \%$ (coefficient of variance).

\section{Fluorimetric NAP activity assay for quantitation of neutrophils adhesion}

The fluorimetric NAP activity assay was introduced to quantify adherence of neutrophils activated or not with TNF- $\alpha$ or pretreated with genistein. The results obtained in the NAP activity assay were referred to those of the MTT reduction test.

As it was shown in Figure 4, the fluorescence intensity measured in the NAP activity test applied for determination of TNF- $\alpha$-stimulated neutrophil adhesion was linear over a wide range of cell numbers $\left(10^{4}-10^{6}\right.$ cells/well). The lin-

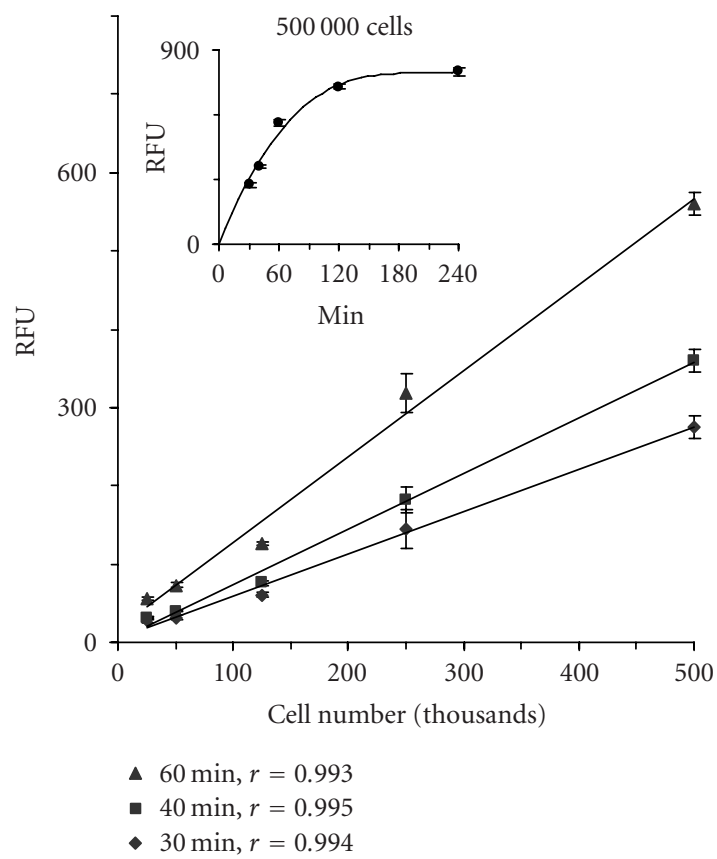

FIGURE 2: The linear relationship between neutrophil quantity and fluorescence intensity measured after different times of cells incubation with the 4-MUP substrate. The cell suspensions at the range of cell numbers $2.5 \times 10^{4}-5 \times 10^{5}$ were centrifuged and lysed with $500 \mu \mathrm{L}$ of the Triton X-100 buffer containing the 4-MUP substrate $(25 \mu \mathrm{g} / \mathrm{mL})$, then incubated 30,40 , or 60 minutes. The fluorescence intensity (RFU-relative fluorescence units) was measured in 96well black plates in four repeats for each cell number. Each point represents the average fluorescence intensity \pm SEM.

earity of the MTT reduction measurements was limited to the cell number range $10^{5}-10^{6}$ cells/well in adhesion assay (Figure 4). The intertest variability was less than $8 \%$ (coefficient of variance).

The applicability of the fluorimetric NAP activity assay was tested for quantification of TNF- $\alpha$-stimulated neutrophils adhesion in the relationship to the activator dose. The results obtained were compared to the results of the MTT reduction test. The NAP activity assay showed dosedependent neutrophil adhesion related to TNF- $\alpha$ concentration (Figure 5). The maximum effect was found at TNF- $\alpha$ $20 \mathrm{ng} / \mathrm{mL}(240.1 \pm 37.3 \mathrm{RFU})$ versus control $(88.5 \pm 21.0 \mathrm{RFU})$ $(P<.0001$, ANOVA/Dunnett's test). The results correspond to those obtained by the MTT reduction test $(20 \mathrm{ng} / \mathrm{mL}$ of TNF- $\alpha 0.149 \pm 0.056$ versus control $0.049 \pm 0.020$ OD; $P<.05$, ANOVA/Dunnett's test) (Figure 5).

The NAP activity assay was also applied for determination of the genistein-induced inhibition of TNF- $\alpha$-stimulated neutrophil adhesion. A significant adhesion inhibition was found at genistein concentrations: $1 \mu \mathrm{M}(P<.05), 10 \mu \mathrm{M}$ $(P<.02), 50 \mu \mathrm{M}(P<.0001$; ANOVA/Dunnett's test $)$ using the NAP activity assay, while in the MTT reduction test the significant inhibition was detectable at the highest dose of genistein $50 \mu \mathrm{M}$ only $(P<.05$ ANOVA/Dunnett's test $)$ (Figure 6). 


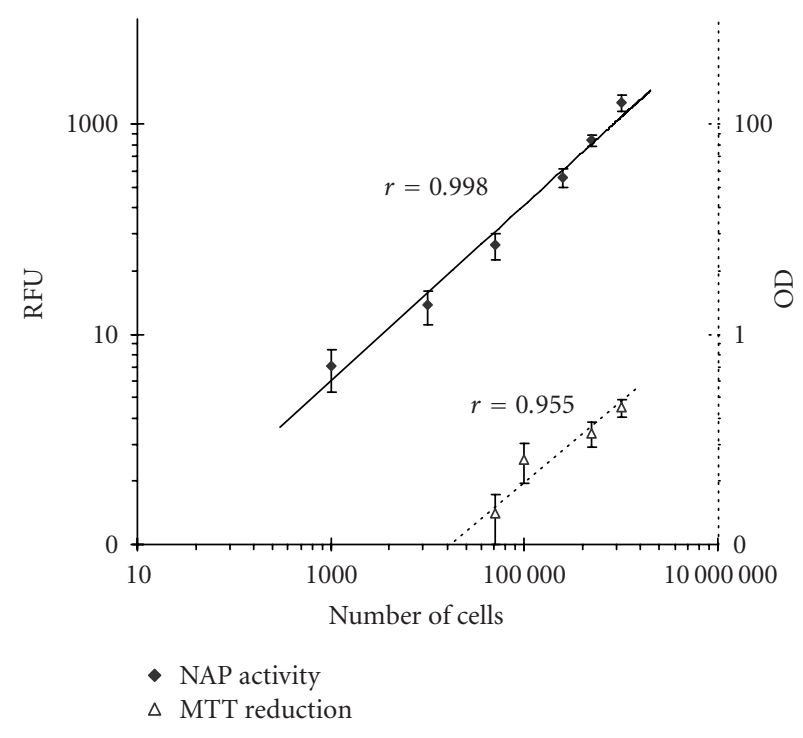

FIGURE 3: The total neutrophil alkaline phosphatase activity (NAP activity) and total MTT reduction in the relation to the cell number. Data are expressed as mean values \pm SEM calculated for 8 donors. The lines represent linear regression analysis. The cell suspensions at the range of the cell numbers $10^{3}-10^{6}$ were centrifuged and subjected to the NAP activity as well as MTT reduction tests. The fluorescence intensity (RFU; NAP activity test) and optical density (OD; MTT reduction test) were measured in triplicates.

\section{Correlation of assays}

The correlation between NAP activity and MTT reduction methods applied for neutrophil adhesion was calculated for different cell numbers, neutrophils stimulated with different doses of TNF- $\alpha$ and for neutrophils treated with genistein. The analyses showed that data obtained by both NAP activity and MTT reduction assays were linearly correlated in all adhesion experiments $(P<.00001)$ (Figures $7(\mathrm{a}), 7(\mathrm{~b})$, and $7(\mathrm{c})$ ). A very high correlation coefficient for the NAP activity and MTT reduction data for the experiments with neutrophils stimulated with TNF- $\alpha$ at different cell numbers $(r=0.933)$ was noted (Figure 7(c)). A high correlation coefficient of both methods compared was found for adhesion experiments with neutrophils stimulated with different doses of TNF- $\alpha(r=0.892)$ and neutrophils treated with genistein $(r=0.875)$ (Figures 7(a) and 7(b)).

\section{Interferences of TNF- $\alpha$ in NAP activity and MTT reduction tests}

Data show that the TNF- $\alpha$-stimulation did not affect endogenous NAP activity. No significant differences were noted between the fluorescence intensity measured in the cell lysates of TNF- $\alpha$-stimulated and nonstimulated neutrophils (307.2 \pm 40.4 versus $298.6 \pm 32.6 \mathrm{RFU}$; pair-wised Student $t$ test). The results obtained in the total MTT reduction test were over-estimated $(18.4 \pm 1.3 \%)$ in the neutrophils stimulated with TNF- $\alpha$ in comparison to nonstimulated ones $(0.186 \pm 0.013$ versus $0.157 \pm 0.026 \mathrm{OD} ; P<.002$, pair-wised Student $t$ test).

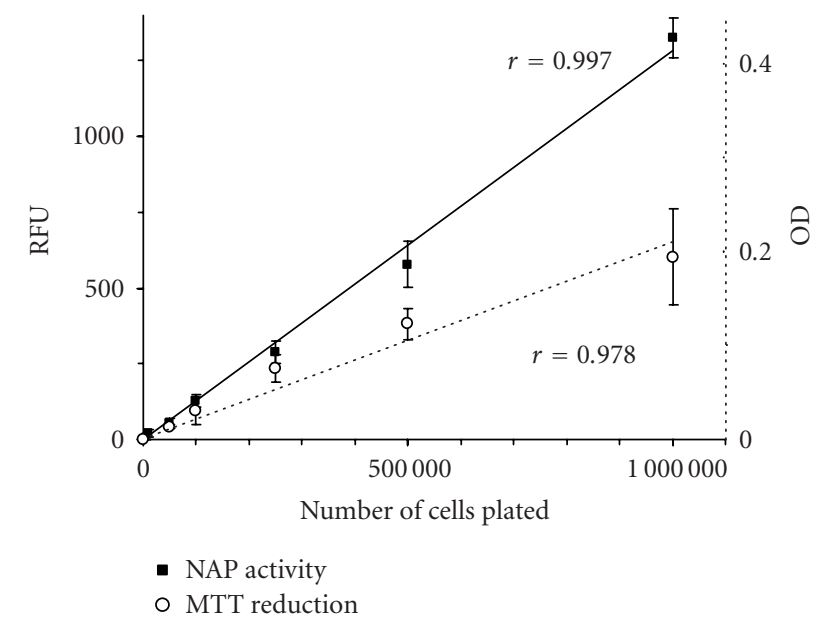

FIgURE 4: The TNF- $\alpha$-stimulated neutrophil adhesion quantified by means of the NAP activity (RFU) and MTT reduction (OD) tests. Aliquots of $1 \mathrm{~mL}$ of neutrophil suspension at cell concentration range $10^{3}-10^{6}$ cells in RPMI medium were transferred to 24well dishes, stimulated with TNF- $\alpha(20 \mathrm{ng} / \mathrm{mL})$ and the endogenous NAP activity (solid line) as well as MTT reduction (dotted line) was measured in the adhered cells to determine neutrophil adhesion.

The neutrophils stimulated with TNF- $\alpha(10-100 \mathrm{ng} / \mathrm{mL})$ did not release alkaline phosphatase into the cellular medium. The fluorescence intensity measured in the supernatants of the neutrophils $\left(2 \times 10^{6} \mathrm{cells} / \mathrm{mL}\right)$ did not significantly differ between $100 \mathrm{ng} / \mathrm{mL}$ TNF- $\alpha$-stimulated (40.1 \pm $2.4 \mathrm{RFU})$ and nonstimulated ( $46.4 \pm 2.7 \mathrm{RFU})$ neutrophils.

\section{DISCUSSION}

We report here the usefulness of the fluorimetric determination of intracellular alkaline phosphatase content as a valuable tool for studying neutrophil adhesion in vitro. We showed that the endogenous NAP activity survey using of 4-MUP substrate in standardized conditions was simple and repeatable with an intertest variability less than $8 \%$. We found that this method applied for neutrophil quantity determination was linear at the wide cell number range from $10^{3}$ to $10^{6}$ (the detection limit $2.4 \times 10^{3}$ cells) and may be applied to the neutrophil adhesion assay. The results obtained by the fluorimetric NAP activity test were linearly correlated with those of the reference MTT reduction test, but NAP test was linear at a wider range of cell numbers $\left(10^{4}\right.$ to $\left.10^{6}\right)$. Our results showed that the total cellular NAP activity was not affected by the stimulation of neutrophils with TNF$\alpha$, which is an inherent advantage over the reference MTT reduction test (18\% over-estimation in TNF- $\alpha$-stimulated cells). Even the highest dose of TNF- $\alpha$ used $(100 \mathrm{ng} / \mathrm{mL})$ did not result in alkaline phosphate release from the activated cells.

Under our experimental conditions the assessment of neutrophil adhesion with endogenous alkaline activity was performed on polystyrene-surface plates, but we also recommend the assay for quantification of the neutrophils adhered 


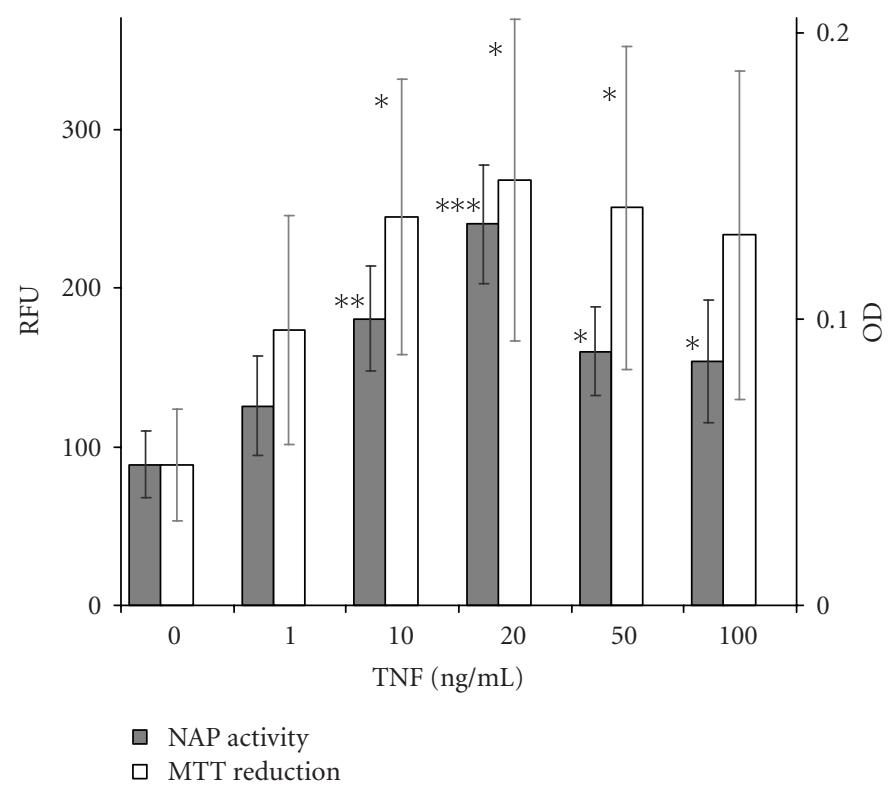

FIGURE 5: Comparison of the NAP activity (RFU) and MTT reduction (OD) tests for the measurement of adhesion of neutrophils activated with different doses of TNF- $\alpha$. Data are mean values \pm SEM of the experiments for 6 donors. Neutrophils were incubated with TNF- $\alpha$ (1$100 \mathrm{ng} / \mathrm{mL}$ ) or without TNF- $\alpha$. Nonadhered cells were removed. Adherent cells were subjected to the NAP activity and MTT reduction tests. Statistical significance: TNF- $\alpha$-stimulated neutrophils versus nonstimulated ${ }^{*} P<.05,{ }^{* *} P<.001,{ }^{* * *} P<.0001$ (ANOVA/Dunnett's test).

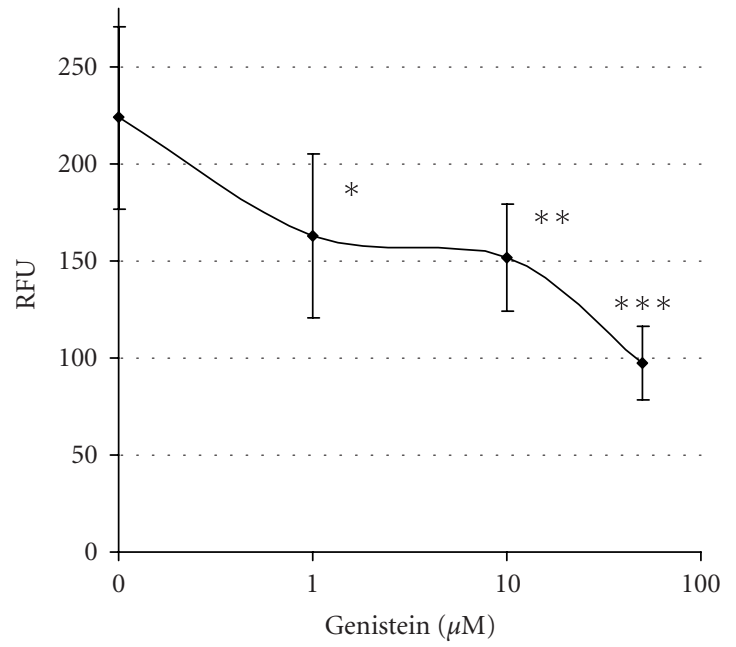

(a)

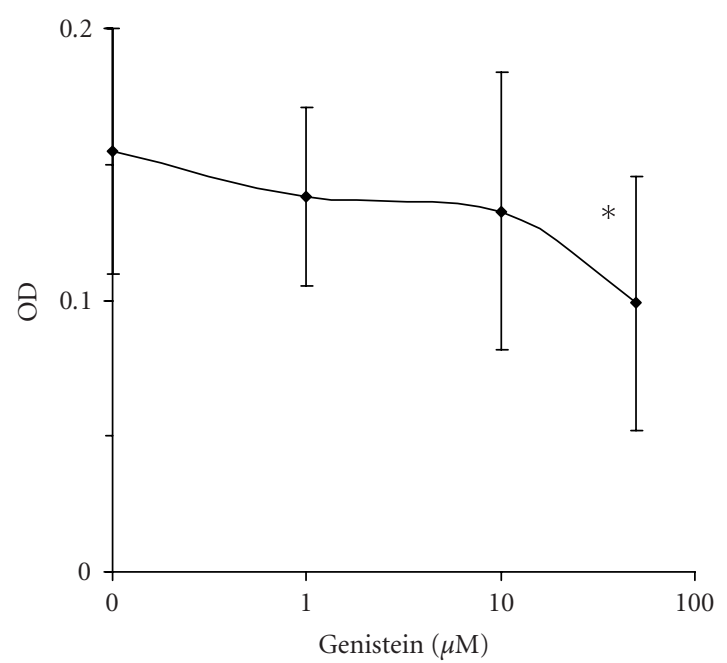

(b)

FIGURE 6: The effect of genistein $(1-50 \mu \mathrm{M})$ on the adhesion of TNF- $\alpha$-stimulated neutrophils measured by both NAP activity (a) and MTT reduction (b) tests. Data are mean values \pm SEM of the experiments for 6 donors. Differences between the results obtained from untreated and genistein-treated neutrophils were compared; ${ }^{*} P<.05$, ${ }^{* *} P<.02$, ${ }^{* * *} P<.0001$ (ANOVA/Dunnett's test). Neutrophils were incubated with genistein at the concentration range $1-50 \mu \mathrm{M}$, and then activated with TNF- $\alpha$ at $20 \mathrm{ng} / \mathrm{mL}$. Nonadhered cells were removed. Adherent cells were subjected to the NAP activity (RFU) and MTT reduction (OD) tests.

to modified surfaces (adhesion protein-coated plates). The adhesion assay recommended herein is also useful for different plates geometry (24-well and 96-well).

We ascertained that the color agents like methylene blue did not interfere with the fluorimetric method, which is an additional advantage over the colorimetric MTT test (data not shown). Additionally we found that fMLP and PMA, widely used neutrophil activators, or genistein and methylene blue dye had no effect on the total cellular NAP activity (data not shown). However, it should be mentioned that exocytosis of the enzyme into extracellular space upon stimulation of neutrophils with the agents such as AIF4 and 


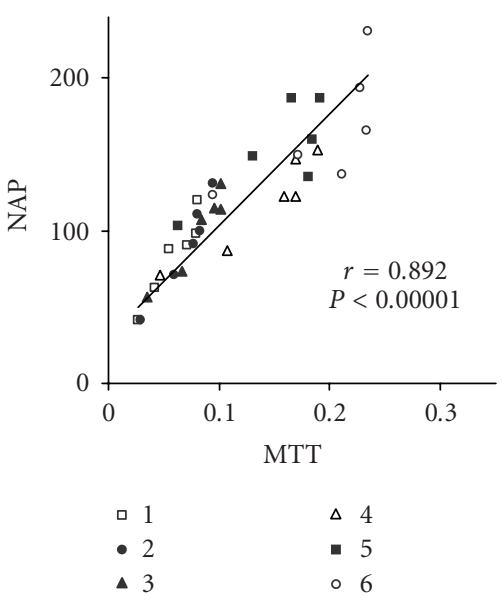

(a)

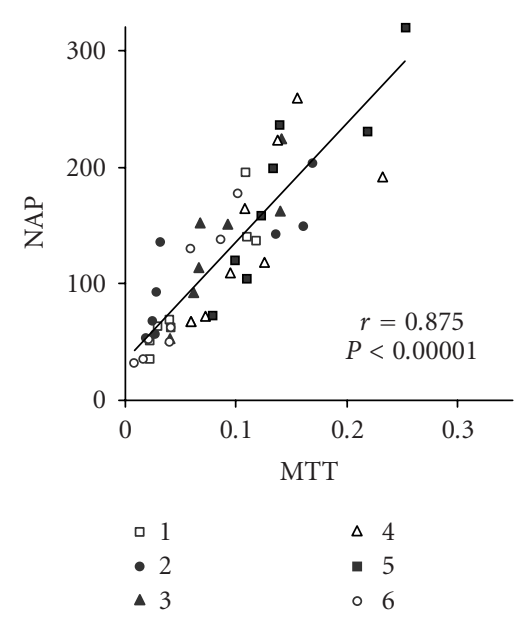

(b)

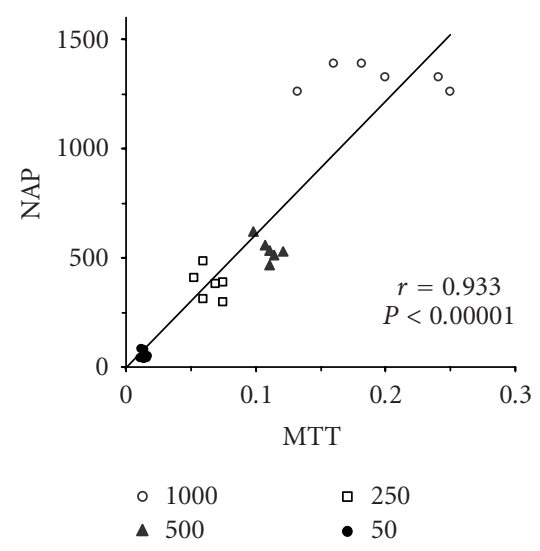

(c)

FIGURE 7: The correlation of data obtained in NAP activity and MTT reduction tests applied for determination of neutrophils adhesion. (a) Neutrophils activated with different doses of TNF- $\alpha(1-100 \mathrm{ng} / \mathrm{mL})$ or nonactivated. Data for 6 individual donors (1-6) are plotted; (b) neutrophils treated with genistein $(1-50 \mu \mathrm{M})$, and then activated with TNF- $\alpha(20 \mathrm{ng} / \mathrm{mL})$ or nonactivated. Data for 6 individual donors $(1-$ 6) are plotted; (c) neutrophils activated with TNF- $\alpha(20 \mathrm{ng} / \mathrm{mL})$ at the range of cell numbers (50-1000 thousands cells/well). Data collected from 6 individual donors. The lines are results of correlation analysis ( $r$ : Pearson product moment correlation coefficient).

$\mathrm{N}$-formyl peptides is possible [22], thus the additional control measurements of NAP activity in the supernatants from non-adhered cells should be taken into consideration.

However, the enzyme content may be lowered in the neutrophils of the patients with specific granule deficiency [23] or elevated in pregnant women [24]. Reduced or absent NAP activity is also found in neutrophils from patients with chronic myeloid leukemia [25]. Moreover, the alkaline phosphatase content per cell may be increased during infection [26]. Thus, in such cases the measurement of the enzyme activity in the sample of total cell number should be performed simultaneously with the adhesion assay and taken into consideration in result calculations.

In summary, the alkaline phosphatase survey with the use of fluorogenic substrate 4-MUP is recommended herein as a sensitive, repeatable, simple, reliable, and not expensive method for determination of neutrophil adherence in vitro.

\section{REFERENCES}

[1] Jutila MA. Leukocyte traffic to sites of inflammation. APMIS. 1992;100(3):191-201.

[2] Sørensen O, Borregaard N. Methods for quantitation of human neutrophil proteins, a survey. Journal of Immunological Methods. 1999;232(1-2):179-190.

[3] Oez S, Welte K, Platzer E, Kalden JR. A simple assay for quantifying the inducible adherence of neutrophils. Immunobiology. 1990;180(4-5):308-315.

[4] Klink M, Cedzyński M, St Swierzko A, Tchórzewski H, Sułowska Z. Involvement of nitric oxide donor compounds in the bactericidal activity of human neutrophils in vitro. Journal of Medical Microbiology. 2003;52(4):303-308.

[5] Mosmann T. Rapid colorimetric assay for cellular growth and survival: application to proliferation and cytotoxicity assays. Journal of Immunological Methods. 1983;65(1-2):55-63.
[6] Pozzolini M, Scarfí S, Benatti U, Giovine M. Interference in MTT cell viability assay in activated macrophage cell line. Analytical Biochemistry. 2003;313(2):338-341.

[7] Rollino C, Borsa S, Bellone G, Piccoli G, Emanuelli G. False positive results with MTT assay. Journal of Immunological Methods. 1995;185(1):141-143.

[8] Akeson AL, Woods CW. A fluorometric assay for the quantitation of cell adherence to endothelial cells. Journal of Immunological Methods. 1993;163(2):181-185.

[9] Maeda Y, Tanaka K, Koga Y, et al. A simple quantitative in vitro assay for thymocyte adhesion to thymic epithelial cells using a fluorescein diacetate. Journal of Immunological Methods. 1993;157(1-2):117-123.

[10] Heimbürger M, Lerner R, Palmblad J. Effects of antirheumatic drugs on adhesiveness of endothelial cells and neutrophils. Biochemical Pharmacology. 1998;56(12):1661-1669.

[11] De Clerck LS, Bridts CH, Mertens AM, Moens MM, Stevens WJ. Use of fluorescent dyes in the determination of adherence of human leucocytes to endothelial cells and the effect of fluorochromes on cellular function. Journal of Immunological Methods. 1994;172(1):115-124.

[12] Tolosa E, Shaw S. A fluorogenic assay of endogenous phosphatase for assessment of cell adhesion. Journal of Immunological Methods. 1996;192(1-2):165-172.

[13] Huschtscha LI, Lucibello FC, Bodmer WF. A rapid micro method for counting cells "in situ" using a fluorogenic alkaline phosphatase enzyme assay. In Vitro Cellular \& Developmental Biology. 1989;25(1):105-108.

[14] Vergnes H, Grozdea J, Corberand J. Liver- and placenta-like alkaline phosphatases (EC 3.1.3.1) isoenzymes in normal human neutrophils. Enzyme. 1984;31(3):154-165.

[15] Borregaard N, Miller LJ, Springer TA. Chemoattractantregulated mobilization of a novel intracellular compartment in human neutrophils. Science. 1987;237(4819):1204-1206.

[16] Borregaard N, Kjeldsen L, Sengelov H, et al. Changes in subcellular localization and surface expression of L-selectin, alkaline phosphatase, and Mac-1 in human neutrophils during 
stimulation with inflammatory mediators. Journal of Leukocyte Biology. 1994;56(1):80-87.

[17] Santini GF, Battistin S, De Paoli P, Villalta D, Boran M, Basaglia G. A method for the determination of the adherence of granulocytes to microtitre plates. Journal of Immunological Methods. 1987;100(1-2):153-156.

[18] Roberts IM, Jones SL, Premier RR, Cox JC. A comparison of the sensitivity and specificity of enzyme immunoassays and time-resolved fluoroimmunoassay. Journal of Immunological Methods. 1991;143(1):49-56.

[19] Gee KR, Sun W-C, Bhalgat MK, et al. Fluorogenic substrates based on fluorinated umbelliferones for continuous assays of phosphatases and $\beta$-galactosidases. Analytical Biochemistry. 1999;273(1):41-48.

[20] Caughey B, de Marco L, Peters TJ, Mashiter K, Gibbons WA. Analytical subcellular fractionation of rat pituitary homogenates with special reference to the subcellular localization and properties of alkaline phosphatases. Biochimica et Biophysica Acta. 1983;757(3):296-301.

[21] Kelly SA, Goldschmidt-Clermont PJ, Milliken EE, Arai T, Smith EH, Bulkley GB. Protein tyrosine phosphorylation mediates TNF-induced endothelial-neutrophil adhesion in vitro. American Journal of Physiology. Heart and Circulatory Physiology. 1998;274(2 pt 2):H513-H519.

[22] Kobayashi T, Zinchuk VS, Okada T, Del Saz EG, Seguchi H. Intracellular dynamics of alkaline phosphatase-containing granules in electropermeabilized human neutrophils. Histochemistry and Cell Biology. 1998;110(4):395-406.

[23] Boxer LA, Smolen JE. Neutrophil granule constituents and their release in health and disease. Hematology/Oncology Clinics of North America. 1988;2(1):101-134.

[24] Fait V, Sela S, Ophir E, et al. Peripheral polymorphonuclear leukocyte priming contributes to oxidative stress in early pregnancy. Journal of the Society for Gynecologic Investigation. 2005;12(1):46-49.

[25] Stagno F, Guglielmo P, Consoli U, Fiumara P, Longo GS, Giustolisi R. All-trans-retinoic-acid- and growth-factor- mediated induction of alkaline phosphatase activity in freshly isolated chronic myeloid leukemia cells. Acta Haematologica. 1999; 102(2):61-65.

[26] Karlsson A, Khalfan L, Dahlgren C, Stigbrand T, Follin P. Neutrophil alkaline phosphatase activity increase in bacterial infections is not associated with a general increase in secretory vesicle membrane components. Infection and Immunity. 1995; 63(3):911-916. 


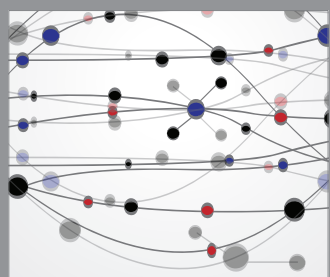

The Scientific World Journal
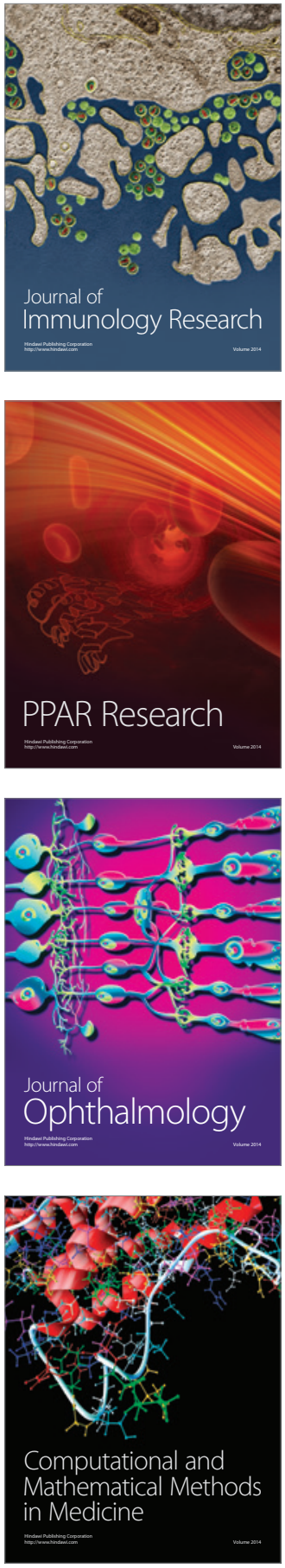

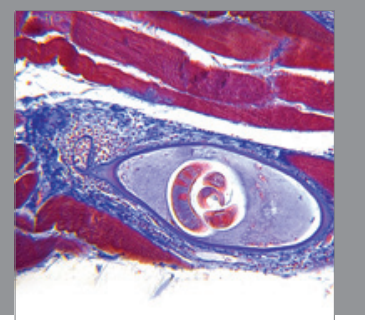

Gastroenterology

Research and Practice
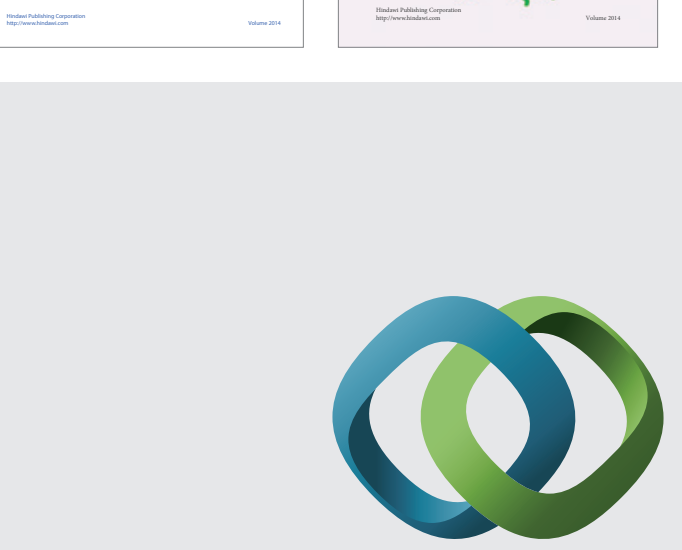

\section{Hindawi}

Submit your manuscripts at

http://www.hindawi.com
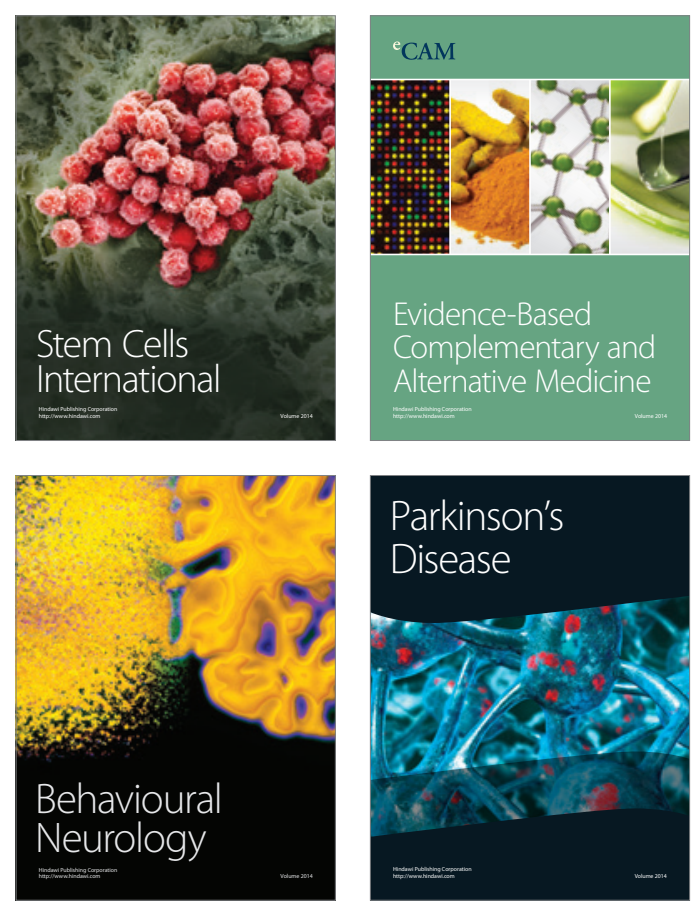

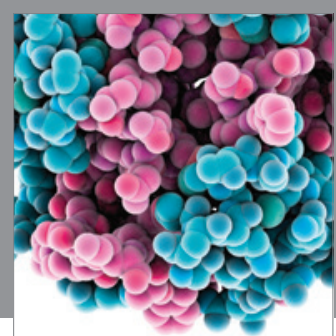

Journal of
Diabetes Research

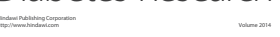

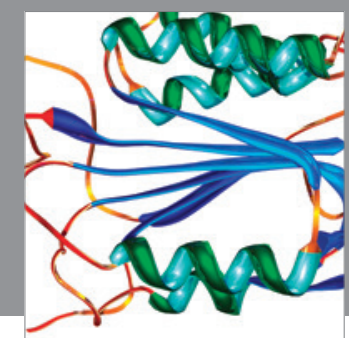

Disease Markers
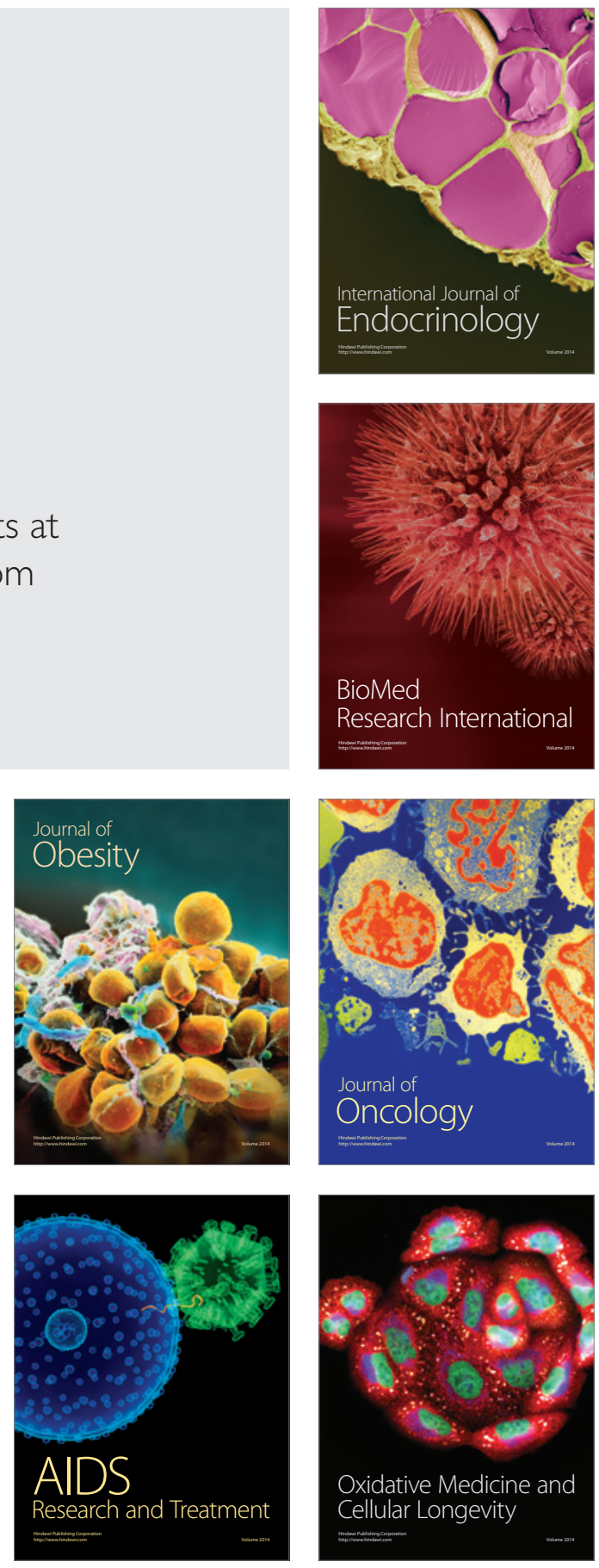